\title{
Role model: Alex Ball
}

\section{The rehabilitation medicine consultant tells Adrian O'Dowd why it's important to help younger doctors navigate the NHS and thrive as clinicians}

\section{Adrian O’Dowd}

London, UK

Alex Ball, consultant and clinical lead in rehabilitation medicine at Haywood Hospital, Stoke-on-Trent, is a passionate teacher who finds tailored solutions to patients' problems.

She qualified from Birmingham University Medical School in 1994 and enjoyed emergency medicine, geriatrics, and psychiatry as a junior doctor. But, by chance, she ended up choosing a different path.

"I took some time out to do informal work as a locum for a couple of months and I was lucky enough to secure a senior house officer position in a brain injury rehab unit in Birmingham," she explains. "It opened my eyes to this wonderful specialty called rehabilitation medicine. I met my role model and consultant mentor there and set about specialist training."

This area of medicine appealed to her, she says. "I like plain speaking, pragmatic medicine where you tailor your advice to fit the individual needs of some of the most complex patients," she says.

"The beauty of neurological rehab is that the conditions we treat give a really diverse array of problems affecting all different systems," she adds.

"For every specialty, the patient is unique, but in rehabilitation medicine you must consider their social circumstances, their job, their relationships, their role in society. You plan rehabilitation goals taking all of that into account and you tailor your advice to fit the person in the real world."

Ball has various roles including clinical lead for trauma rehabilitation at Royal Stoke University Hospital and rehabilitation lead for the Midlands Critical Care and Trauma Network.

Asked what she loves most about her job, she says, "It's the privilege of sharing a journey like brain injury with a patient from critical care right through to the day when they might go back to work or get into college or go back to some form of training. I'm in touch with patients and families throughout that whole journey. No two are ever the same."
Ball is also an examiner for Keele University Medical School and for the Royal College of Physicians. "The thing I enjoy most about teaching is making things simple," she says. "I love it when I can help students or trainees to understand things." In addition, Ball mentors newly qualified consultants. "I think mentoring is essential," she says. "The NHS is a tough place to work and doctors are under unprecedented levels of pressure from all angles. You often need somebody to help you navigate the system and make wise choices. I like being able to help people see the possibilities that are open to them and give them confidence."

Her advice to newly qualified doctors and medical students is simple. "Look after yourself," she says. "Look at your lifestyle, keep yourself healthy, take on realistic amounts of work, and remember that you are important and that you will only be of use to your patients if you are a role model for looking after yourself."

\section{Nominated by Simon Exton}

Dr Ball was an inspiring supervisor during my core medical training, emphasising the importance of a global, patient centred view of medicine in addition to focussing on management of the immediate clinical problem.

She encourages engagement with the multidisciplinary team and also the value of innovative, tailored solutions to patients' problems. Working in her team as a trainee was such a positive experience that I and some of her other previous trainees returned to work for her as specialty doctors.

She is a passionate, engaging teacher both in a formal setting and with more practical, clinical teaching. She, above any other trainer, helped get me to the point where I passed my practical assessment of clinical examination skills examination first time. She also encourages her trainees to follow and achieve their ambitions.

Simon Exton is a registrar in Immunology, working in Hull

Nominate a role model: To nominate someone who has been a role model during your medical career, send their name, job title, and the reason for your nomination to arimmer@bmj.com

Published by the BMJ Publishing Group Limited. For permission to use (where not already granted under a licence) please go to http://group.bmj.com/group/rights-licensing/ permissions 